\title{
Adding a "Design Thread" to Electrical and Computer Engineering Degree Programs: Motivation, Implementation, and Evaluation
}

\section{Dr. Alan Cheville, Bucknell University}

Alan Cheville studied optoelectronics and ultrafast optics at Rice University, followed by 14 years as a faculty member at Oklahoma State University working on terahertz frequencies and engineering education. While at Oklahoma State, he developed courses in photonics and engineering design. After serving for two and a half years as a program director in engineering education at the National Science Foundation, he took a chair position in electrical engineering at Bucknell University. He is currently interested in engineering design education, engineering education policy, and the philosophy of engineering education.

\section{Dr. Michael S. Thompson, Bucknell University}

"Stu" is an associate professor in the department of Electrical and Computer Engineering at Bucknell University, in Lewisburg, PA. While his teaching responsibilities typically include digital design, computerrelated electives, and senior design, his focus in the classroom is to ignite passion in his students for engineering and design through his own enthusiasm, open-ended student-selected projects, and connecting engineering to the world around them. He spends a great deal of time looking for ways to break out of the traditional engineering mold and to make engineering more broadly accessible to students. His research interest is the application of mobile computing to interesting, human-focused problems. He holds three degrees in computer engineering including graduate degrees from Virginia Tech and an undergraduate degree from NC State University.

\section{Dr. Stewart Thomas, Bucknell University}

Stewart Thomas is an Assistant Professor in the Department of Electrical and Computer Engineering at Bucknell University in Lewisburg, Pennsylvania. He received the B.S. and M.Eng. in Electrical Engineering from the University of Louisville in Louisville, KY. and the Ph.D. in Electrical and Computer Engineering from Duke University in Durham, North Carolina. He is a member of ASEE and IEEE. 


\title{
Adding a "Design Thread" to Electrical and Computer Engineering Degree Programs: Motivation, Implementation, and Evaluation
}

\begin{abstract}
This article details the multi-year process of adding a "design thread" to a four year, undergraduate electrical and computer engineering curricula. We use the conception of a "thread" to mean a sequence of courses that extend unbroken across each year of the undergraduate curriculum. The design thread includes a project-based introduction to the discipline course in the first year, a course in the second year focusing on measurement and fabrication, a course in the third year to frame technical problems in societal challenges, and culminates with our two-semester, client-driven fourth-year capstone design sequence.

The impetus to create a design thread arose from preparation for an ABET visit where we identified a need for more "systems thinking" within the curriculum. Here systems thinking refers to understanding abstraction and its relation to system decomposition and modularity; students having difficulty making engineering evaluations of systems based on data; and students' difficulty transferring skills in testing, measurement, and evaluation from in-class lab scenarios to more independent work on projects. We also noted that when working in teams, students operated more collectively than collaboratively. In other words, rather than using task division and specialization to carry out larger projects, students tended to address all problems collectively as a group.
\end{abstract}

This paper discusses the multi-year process through which faculty developed a shared conception of design to enable coherent changes to courses in the four year sequence and the political and practical compromises needed to create the design thread. To develop a shared conception of design, faculty explored several frameworks that emphasized multiple aspects of design. Course changes based on elements of these frameworks included introducing design representations such as block diagrams to promote systems thinking in the first year and consistently utilizing these representations throughout the remainder of the four year sequence. Emphasizing modularity through representations also enabled introducing aspects of collaborative teamwork. While students are introduced broadly to elements of the design framework in their first year, later years emphasize particular aspects. The second year course focuses on skills in fabrication and performance measurement while the third year course emphasizes problem context and users, in an iterative design process. The client-based senior capstone experience integrates all seven aspects of our framework.

On the political and organizational side, implementing the design thread required major content changes in the department's introductory course, and freeing up six credit-hour equivalents, one and a half courses, in the curriculum. The paper discusses how the ABET process enabled these discussions to occur; how other curricular changes needed to enable the design thread to be implemented were accomplished; and the methods used to enable the two degree programs to align faculty motivation, distribute the workload, and understand the impact the curricular 
changes had on student learning. This case study provides an in-depth analysis of a curricular change process that could be informative for other programs hoping to make such changes.

\section{Introduction and Institutional Context}

This paper describes the ongoing evolution of a small electrical and computer engineering (ECE) department at a liberal arts institution over a time period in which major curricular change was planned and implemented. The paper is written as a descriptive, atheoretical case study. In the work discussed here the ongoing changes (evolution) of the program is primarily articulated through curricular changes. While many other factors can influence change processes [1], [2], these factors are not discussed in depth in this paper, which focuses on visible activities rather than the beliefs, values, and attitudes that underlie action. The paper discusses the motivating factors for change, the process that followed, the resulting curricular changes, and the lessons learned from undertaking a significant curricular change. Given that every department and university has their own culture, the paper focuses on the aspects of the process that are most transferable to other institutions.

Private, mid-Atlantic, Liberal Arts CollegE (PALACE) is a medium-sized, elite, primarily-white liberal arts institution that is located in a rural area in the mid-Atlantic region. PALACE is similar to many other liberal arts universities, but has three colleges including arts \& sciences, engineering, and management. The College of Engineering has six departments that offer a set of engineering programs that do not differ greatly from those at other universities. Each department currently has a great deal of autonomy regarding their curriculum within the structure of the University.

Two aspects of PALACE's structure are distinctive when compared with that of other universities. First, the university follows a "credit" system, as opposed to a "credit hour" system, with the expectation that a one credit course is four credit hours. Students in engineering must receive 34 credits to graduate; equivalent to 136 credit hours. The ECE curriculum consists of 32 one-credit and four half-credit courses. Engineering students take 4.0 or 4.5 credits per semester, or 16 to 18 credit hours. Second, PALACE has a strict requirement that students graduate in eight semesters in order to both ease financial constraints for students and the institution and maintain a strong four year graduation rate. There are several aspects of this institutional requirement that impact the curriculum. First, students who drop or do not pass a course will typically make up the credit at other institutions during the summer as PALACE mostly offers courses during the fall and spring semesters. Second, as PALACE is in the fourth quartile of engineering school size [3], most courses are taught once per year, potentially leaving students who do not make up credits one year behind.

Within these institutional aspects, the ECE department offers two degree programs. One in electrical engineering (EE) and one in computer engineering (CPE). The CPE program was created to boost enrollment at a time when the number of EE graduates hit a nadir nationally [4]. This program was jointly developed with the computer science (CS) department, and students take some CS courses in addition to ECE courses. Currently the ECE department has approximately 100 students distributed evenly across all four years of the curriculum. Approximately $60 \%$ of the students are in the EE program and $40 \%$ are in the CPE program. The department also offers a Masters degree in EE. PALACE, as a predominantly undergraduate 
institution, does not offer any Doctoral degrees. The lack of graduate students is a constraint on program development and new offerings since the work burden falls predominantly on the faculty.

The ECE Department itself is composed of ten tenure track faculty with two support staff; one office staff member and one lab staff member. Of the ten faculty, seven have backgrounds in EE and three have backgrounds in CPE; there was some faculty turnover during the period this case study reports on. Faculty appetite for change varied with some faculty eager to change programs while others saw value in the existing curriculum. At PALACE, faculty have a five course annual teaching load; faculty teach all classes and associated labs since there are no $\mathrm{PhD}$ students.

Prior to 2016 the ECE Department had a fairly traditional curriculum that had not undergone any significant changes in decades. This curriculum met ABET criterion 5 guidelines with eight credits (32 credit hour equivalent) of math and science courses, primarily taken in the first two years. Besides math and science, the first two years were heavy on general engineering and computer programming courses (three credits, 12 credit hour equivalent) and introductory ECE courses (three credits, 12 credit hour equivalent). The last two years of the curriculum focused on more specialized topics and technical electives, with the third year particularly heavy in required technical courses. Five university-mandated general electives and three open electives were distributed across the four years, with more in the fourth year of study. Overall, the content of the courses was similar to most other institutions and both ECE degree programs included topics such as circuit analysis, electronics, signals and systems, probability, digital logic, microcontrollers, and programming. The EE program also included the topics of power, control systems, and mechanics while the CPE program included additional/advanced programming, data structures, discrete math, operating systems, and algorithms. Across all ECE courses, the program advertised itself as being "lab intensive" by providing many hands-on opportunities. Almost every ECE course included a two- to three-hour lab component in addition to three hours of lecture each week. Although this amounts to six contact hours per week, it is worth noting that students still receive only one credit for the course and lab combination. In terms of design, students encountered a "bookend" [5] curriculum with a short project in the first semester of the first year and a year-long capstone sequence in the fourth year.

\section{Motivation}

As several authors who examine change processes have pointed out, wide scale programmatic change in higher education is rather rare [1], [2], [6], [7]. This section discusses the factors that, in retrospect, coincided to enable large scale curricular change to occur at this particular point in time. These factors, in no particular order, are: 1) reflection prior to and the post-hoc results of an ABET accreditation visit, 2) arrival of an external department chair, 3) a preponderance of younger faculty in the department, 4) lingering pressures from lower-than-desired enrollment, 5) an environment that welcomed educational innovations, 6) a promotion and tenure system that valued teaching, 7) innovations occurring college-wide from a KEEN Foundation grant, and 8) growing institutional stresses caused by external factors not under the institution's control. Each of these factors are described briefly below. 
The first factor was the preparation for, and results of, a 2014 ABET accreditation review which revealed several areas in need of change. One area that the process of preparing for accreditation revealed was that the department had not developed an actionable conception of what it meant to possess the skills and abilities needed to practice electrical or computer engineering. This in turn led to efforts to develop consensus around what constitutes techniques, skills, and modern engineering tools. A second area was the need to provide students more experience in analyzing, conceptualizing, and designing engineered systems by creating opportunities for more open ended and complicated design projects. A third area was strong evidence that more emphasis on working collaboratively was needed - including teamwork as well as a focus on ensuring less prepared students had the same learning opportunities to contribute to labs and projects. The fourth area was data from students indicating communication, especially writing, in engineering contexts needed more emphasis. Upon reflection, these various areas were seen to converge around engineering systems, particularly how they are designed and evaluated.

These areas were identified from multiple program assessments that included direct, rubric-based assessment in capstone design which indicated a lack of understanding of the systemic nature of design. A program-wide survey adapted from James Madison University looked broadly across the curriculum while individual course assessments highlighted areas where results converged. Students also responded to multiple surveys which allowed for open-ended responses, providing qualitative data that was extremely valuable in informing possible new curricular directions.

As noted earlier, the ECE program at PALACE had defined itself for some time as having a labbased and hands-on approach. The dawning recognition that this approach did not accomplish all the goals intended served as an opportunity for many faculty to reconsider the focus of our programs and how we might improve learning outcomes. Such reconsideration was not universal; some individuals firmly believed and continue to believe that a focus beyond the skills and theory needed for laboratory work detracts from the focused nature of the program. In this context, our ABET visit was used as a catalyst for change. Beyond the reflection engendered by the process, following the visit one concern was that curricular limitations did not allow students to take a sufficient number of electives. This finding resulted in faculty more broadly looking at the curriculum rather than just specific, focused changes in existing courses.

The second and third factors - a new chair and young faculty - were simply coincidental since a new, external department chair had been hired less than two years before the ABET visit at a time when $70 \%$ of the faculty in the department had been at PALACE for less than a decade. The hiring of a chair from outside the department, which is not standard procedure at PALACE, was stimulated by low enrollments in the department, (the fourth factor) which reflected national trends in electrical and computer engineering graduates [4]. Given the fact that PALACE is predominately tuition-funded, low enrollment was a cause for administrative concern.

The fifth and sixth factors (environment and reward structures) helped to create conditions in which efforts to improve programs could be recognized. Because PALACE is a predominantly undergraduate institution it places significant emphasis on teaching. Due to growth in the College of Engineering over the prior two decades and the presence of significant on-campus expertise in engineering education research, there was significant interest across the College of Engineering in large-scale efforts to undertake educational innovations. University-wide tenure 
and promotion criteria placed teaching as the primary consideration, and a revision of the department level tenure and promotion criteria by the new chair further clarified the types of activities that would be recognized. The visibility of these efforts were supported in part by the seventh factor, an institutional grant from the KEEN Foundation [8]. This funding supported and allowed for faculty get-togethers in both formal and informal settings, camps, hackathons, course development and other venues where learning opportunities were co-developed. These conversations, that happened before the change effort described here, helped create an attitude that change was indeed possible.

The eighth factor, environmental stressors, is the least definable. As mentioned previously PALACE is predominantly tuition-funded and among those institutions with the highest net costs. In these last decades tuition has increased dramatically while societal income inequalities have also been increasing. These two trends occur at a time in which a college education is perhaps more necessary than ever. While it is easy to become inward-looking at any institution, there was increasing awareness among some faculty and administrators that such external economic and societal factors can influence the academy [1] and this provided an impetus for change.

These eight factors were, in retrospect, elements that enabled serious consideration of curricular revision and also served to guide the direction and process of the change. It is important to note that these were not the only factors that came into play during the change process. It is also important to state that this particular set of conditions is not necessary for change. As described subsequently the changes that came about built from these specific conditions but developed in somewhat of an organic way as the department continued to discover and learn about possible paths forward through dialog, debate, and an evolving focus on design.

\section{The Process}

The entire process from beginning to meaningful engagement in a curriculum change process to graduating our first students under the new curriculum took approximately seven years. A majority of the work was carried out by a rotating membership working group composed of volunteers from within the department. Unlike typical department committees, working groups are structured to be less formal and disband at the end of each year, but may choose to reconstitute, often with new membership. The curricular working group typically had about five members but the composition varied slightly from year to year. We called this group the " 40,000 $\mathrm{ft}$ working group" or "the $40 \mathrm{~K}$ group" since its initial goal was to look broadly at the program without getting bogged down into too many details. The initial charge of the $40 \mathrm{~K}$ working group was to: "Look at the big picture of electrical [and computer] engineering at [PALACE], identifying a handful of 'big ideas' that our curriculum is based upon, and define an overall vision of the program. Develop methods and tools that allow us to look at the curriculum broadly and attempt to develop ways to create better coordination within the curriculum." The group thus started by discussing the visions and objectives of the department, its students, and its faculty and staff. In other words, answering: "What do we want the curriculum to accomplish?"

The group would generate ideas, bring them to the department for comment, and then take the feedback and iterate. Given the small department size (about ten faculty), in general policies are 
informal and adopted without formal voting procedures. Working groups ensure that program changes are interest-driven and involve a critical mass of engaged faculty. However, towards the end of the change process, the working group had to shift focus more toward details of curricular implementation, and thus more time was spent working with the whole department or relevant subsets of the department instead of just the working group. The working group was typically "chaired" by the department chair. Thus, the process began with opportunities for discussion among department members, evolved into a volunteer working group of engaged faculty members maintaining a critical-mass size, and continued in an iterative feedback loop with the department as a whole. The next section discusses some of the processes used to build consensus around a vision change that led to design becoming a major feature of the curriculum.

\section{Building Shared Meaning}

Our first goal was to explore the interests and priorities of those in the department and identify areas of shared focus and those without. The change process started in a Fall 2013 ABET retreat where faculty and staff participated in two thought exercises. For the first exercise, each person was asked to "write down the traits or behaviors you would look for if you were asked to identify a successful ... graduate five years after graduation." Some example cards are shown in Figure 1. The second exercise asked each person to "describe the best undergraduate degree program in electrical or computer engineering in the country. Be specific about features you would look for or questions you would ask if you were asked to determine the best program as an independent, outside observer." Each set of traits was placed on the board. The entire group identified similar traits and clustered them together. This exercise exposed the breadth of our own interests and values but it also showed areas where there was shared interest.

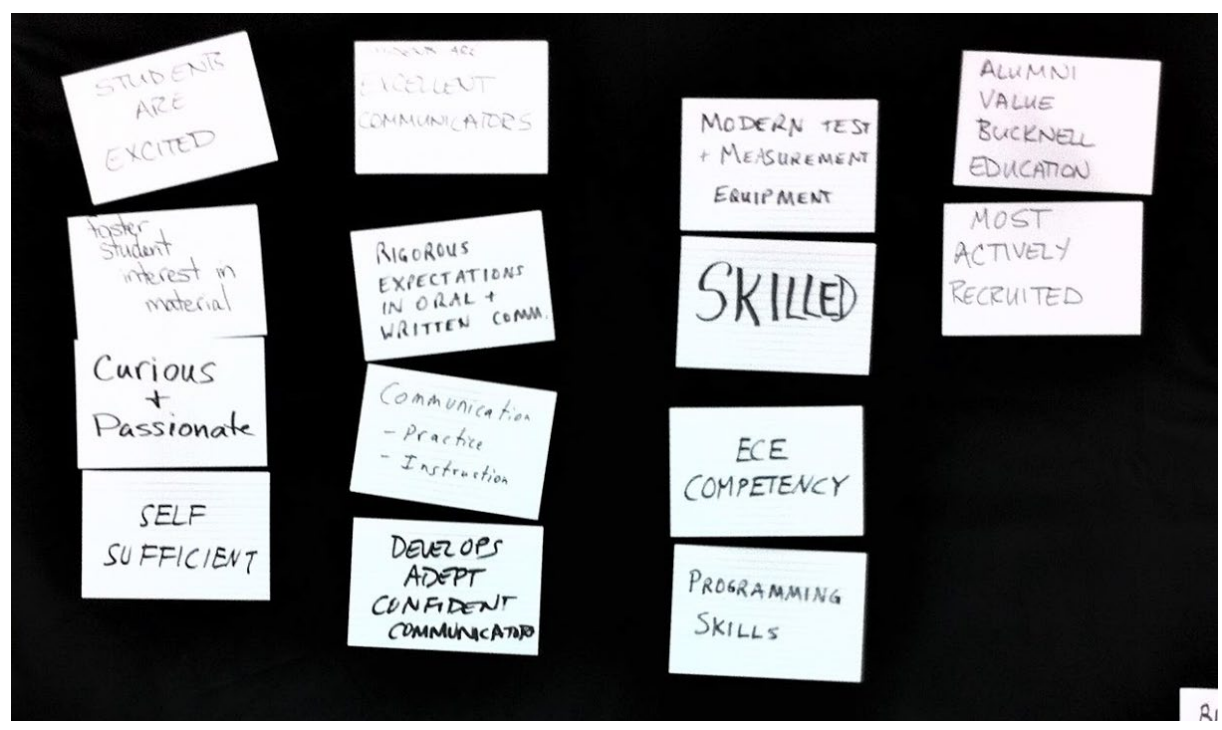

Figure 1 - A subset of the "student trait" cards from the fall 2013 ABET retreat. After everyone added their cards to the wall, the team grouped similar cards together.

The 40K working group took the set of traits from the ABET retreat and the university's mission statement, the university's learning goals, and the college's mission statement and looked carefully for overlap and differences. Items that appeared in multiple places and those the group resonated with were integrated into a concise set of objectives. The specific format for the 
resulting aspirational statement was a bullet list with a word followed by a short description of how that trait (word) applies to a program graduate. An example is: "Aware - we recognize the social and ethical dimensions of engineering."

There were multiple rounds of discussion and negotiation during the weeks that followed until a rough consensus was reached. This process was not without disagreement and not all of the ideas were included. The ideas for the basis of the program that were related to the traditional traits of an engineer were more quickly and widely accepted than those pertaining to professional skills; in other words, non-technical traits were more controversial. For example, at one point there was an objective focused on being "caring" that was controversial and ultimately changed to "collaborative". Another exercise used elements of epistemic stances from Schiro's curriculum theory [9] to help faculty self-identify personal philosophies of education.

While these exercises were time consuming, they were successful to some degree in shifting conversations from an immediate focus on what the end goals of change should be to awareness of an individual's own perspectives and biases. Rather than focusing on what problem to solve, there were substantive discussions of what the goals of an engineering education should be and how they differed from, or agreed with, those of other faculty in the department. It became clear during these exercises that a necessary step was to build shared meaning and a shared lexicon; at the beginning of the process group members held different definitions of the same word, with unstated assumptions of their held definition being a universally shared definition. Because many topics were emotionally charged, small misunderstandings led to heated conversations. One of the key areas of misunderstanding, for example, was on the term "design". Some faculty saw design as an outcome of engineering work while others focused on design as a process. The realization that meaning of common words was not commonly shared modified the group's approach throughout the rest of the process by taking the time to consciously agree on definitions and clarify the beliefs that underlay interpretations in order to communicate more effectively. It is known, for example, that design teams develop common language [10], [11] which was a process the group sought to foreground and work on consciously.

The development of programmatic goals - which eventually led to a new set of ABET Program Educational Objectives - both shifted communication within the department to a different level and clarified the outline of the curricular change process. Acknowledging the existence of dialectics led to possibilities for change. For example, the faculty members involved in the process saw that while the department had seen itself as highly collegial with a shared understanding, in fact prior intra-departmental conversations had not revealed that individuals' conceptions of the ideas behind the words varied widely. Beyond design there were widely different interpretations of terms commonly used in engineering education such as "leadership" and "communication". Recognizing the need to define such terms led to a realization that educational goals and priorities varied as well. A conscious aspect of the process was not to take votes or decide on single interpretations or try to resolve differences, but to recognize differences, achieve workable compromises, and seek to understand the diversity of viewpoints that were present even in a small faculty in order to create an environment in which differences could be discussed openly. It is worth reiterating that in retrospect the goal was not to arrive at a shared vision but to promote understanding. An individual's beliefs and values are grounded in experience and cannot always be logically argued to others or tied to specifics of the change 
process. For many, these discussions touched on aspects of things they had not previously articulated [12].

Another challenge the group faced, related to individual faculty views of what an engineering education should accomplish [9], were deeply held faculty convictions of what engineering should be [13] which was intertwined with individual's identity as an engineering faculty member. Practically, the epistemic stance of engineers as problems solvers, the fact that courses were seen as a product of individual faculty effort, and the challenges in communication identified above meant that proposals for curricular change could be perceived as personal criticism. The fact that change was framed as a problem-i.e. that "something was wrong" or "needed fixing"- meant that discussions about change in specific curricular areas or courses could be viewed as an implicit critique of faculty performance or worth. Such misunderstandings occurred more often when they fell outside of areas of technical expertise such as trying to introduce more professional skills or framing engineering in societal contexts. This was a challenge the $40 \mathrm{~K}$ working group was never able to fully address and may be rooted in broader professional identities and norms of the engineering profession.

Three Basic Competencies - A Framework for ABET Criterion 3

Given these challenges, the $40 \mathrm{~K}$ working group realized that it needed a framework that would be broad enough to cover a wide range of faculty beliefs, but actionable enough to tie specific curricular changes to. ABET is a natural framework since it is essentially mandated for US engineering programs and, since the adoption of EC2000 [14], is putatively focused on continuous program improvement. Furthermore, our curricular change process was stimulated in part by preparation for and in response to an accreditation visit. However in trying to apply ABET's criterion 3 Student Outcomes (SOs) we found the SOs, while understandable individually, did not help us conceptualize how they worked together synergistically to create an engineering graduate. While problem decomposition is a common engineering design method, ABET fails to address synthesis, or how the sum of the parts becomes a whole. The group chose instead to adopt Barnett and Coate's [15] view of curriculum as addressing: 1) knowing engineering, 2) doing engineering, and 3) being an engineer. This framework allowed organization of the ABET SOs in a way that was framed more holistically around student development. As framed in department documents at that time:

Our outcomes are drawn from three competencies that underlie the program's learning objectives:

- knowing the foundational principles of ___ engineering and the context needed to use them,

- possessing the skills to act as an engineer and do engineering, and

- acquiring the professionalism and identity needed to succeed as an engineer. A key point is that the aspects of knowing, acting, and being are not separate competencies and in a___engineer these should be integrated holistically as reflected in our mission and program objectives. The aspects of knowing, doing, and being are framed in the context of a spectrum of engagement that extends from the technical focus needed to learn specifics to larger societal issues [where is either electrical or computer]. 
For example, ABET criterion (a) focused on the ability to apply math and science, which in modified form is now criterion (1), was mapped to knowing engineering. Based on the group's experiences with the importance of having a common definition of words and phrases, we applied the same strategy to each of the ABET outcomes to try to better align curricular change with ABET mandated outcomes. The example below shows how the term "apply" was operationalized and ties the outcome to faculty values which emerged during the departmentwide conversations discussed previously; preserving key values was seen as critical to eventual adoption of change.

(a) an ability to apply knowledge of mathematics, science, and engineering Interpretation: The key word in this outcome is "apply" since our program emphasizes knowledge in the context of electrical and computer engineering. We utilize the definition of apply from the 2001 revision of Bloom's Taxonomy which is "being able to carry out a procedure in a given situation". To show they meet this outcome students should demonstrate they can independently use concepts, facts, and procedures to obtain a result that an expert agrees is correct.

Importance: This outcome is foundational to our program since we pride ourselves on giving students the opportunities to apply knowledge in hands-on laboratory or design experiences. It is expected that most electrical and computer engineering courses integrate some elements of this outcome.

The attempt to operationalize ABET outcomes in terms of knowing, doing, and being as well as clarifying understanding of key terms led to more productive conversations and simplified the process of designing assessment instruments, ultimately aiding the curricular change process. Furthermore, it helped provide consistent definitions of learning outcomes for faculty that were derived from the values shared, for the most part, by department faculty. It is important, however, to clarify the ways that our change process both followed and diverged from the accreditation process. ABET provided an impetus for change by stimulating a deep, departmentwide reflection before the visit and by forcing the program to implement changes to address concerns following the visit. However, because the desired programmatic change was fundamentally ontological, the processes implied by ABET which focuses on continual quality improvement did not by itself provide a usable framework. Nor did the fact ABET is effectively mandated help achieve further buy-in from faculty and other stakeholders in the change process.

\section{Results of the Change Process}

This section describes the changes that have occurred as a result of the processes described above. While mental models of change often contain a dichotomy of "before the change" and "after the change", our experience was that change occurred slowly over time without dramatic shifts or markers. Such slow change is not described by steady progress, rather change can appear more like a random walk, with the direction only slowly becoming apparent over time. Thus this section looks over a relatively long time period, six to seven years, and summarizes shifts that have emerged and were able to be sustained. There were many efforts that were not sustainable which are not described. 
1) Deemphasizing Content: One of the changes engendered by this effort was a shift away from being excessively content-focused. Early on our program assessment was less organized; individual faculty taught and assessed learning outcomes that aligned with their course goals. As a result, outcomes were driven by faculty perceptions of interest and importance which led to patchwork outcomes and assessment. For example: individual course learning outcomes tended to be specific to the course such as "apply small-signal analysis to basic MOSFET and/or BJT amplifier circuits" or "use fundamental techniques of lossless data compression, such as Huffman coding." As the change effort progressed, the use of more curricular-centered (rather than course-centered) frameworks led to more organized discussions that all members of the department participated in. Focusing on common student outcomes led to a better vision of the breadth and depth of the program. Practically, shifting from a course-centric to a curricularcentric view resulted in an increasing realization that some areas were not being well-addressed in the curriculum. This in turn caused some faculty to reconsider course outcomes.

Figure 2 shows the frequency of outcome assessment across all the ABET student outcomes at two points in time several years apart across all courses that directly assess the SOs. It is easy to see there was more focus on some areas and less in others. Without a robust mechanism to discuss broader curricular outcomes in a widely-shared framework, individual faculty focused on content-specific course goals that aligned with knowing engineering, less on doing engineering and even less on being an engineer. The more even distribution in how faculty self-reported learning outcomes across the curriculum (Fig. 2, right side) aligned with shifts in departmentwide conversations. Although not everyone agreed on how to balance outcomes, a key point is simply that having a framework, some data to discuss, and the corresponding conversations gave insights into the curriculum and made the priorities of individual faculty more transparent. One caveat is that changes in student activity were not directly measured by the instrument used to collect this data. Therefore, some of the changes may be due to how faculty self-report activities they do in class.
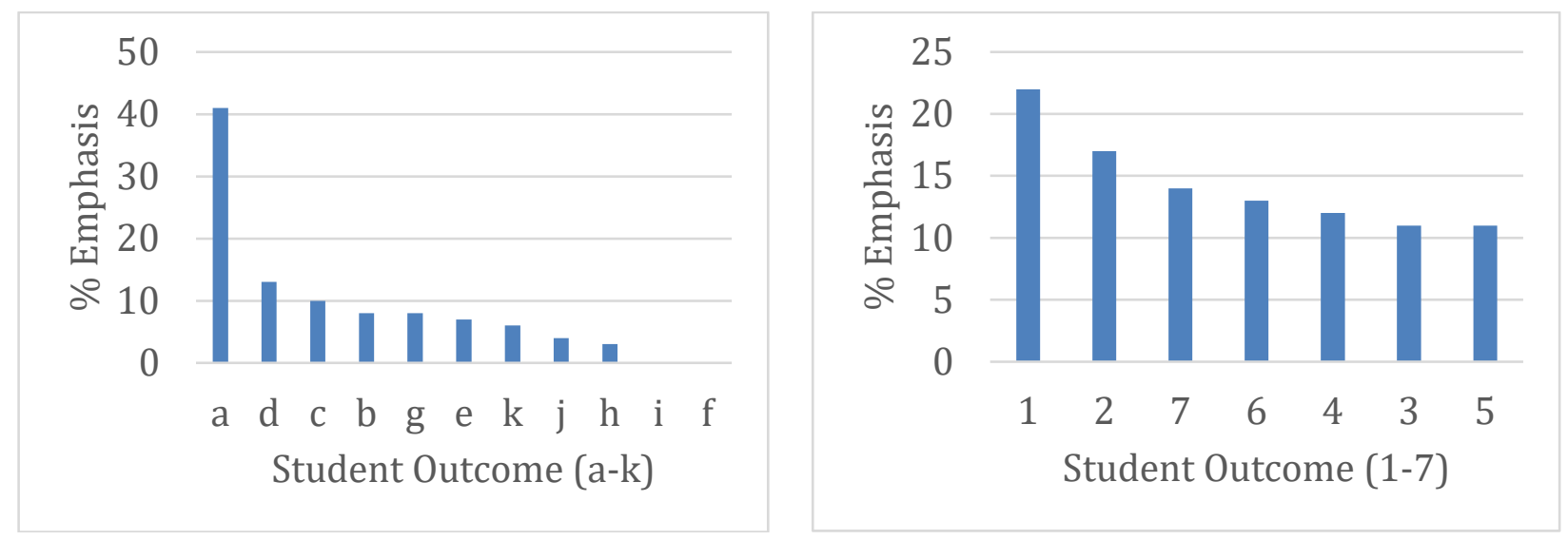

Figure 2 - A comparison of the distribution outcome assessment across courses in the 2015-16 (left) and 2019-20 (right) academic years. 
2) Curricular Reform: As discussed previously, a program's curriculum can be viewed through many lenses. For students (novices in a discipline) it provides information on the ordering and hierarchy of courses (and thus knowledge). For faculty it provides a design constraint as it reflects how a discipline organizes knowledge and is a proxy for what knowledge and activities are valued. For example, the importance of particular content areas is conveyed by the amount of time spent on them; an entire course on a given topic conveys that the topic is important. These decisions extend to how knowledge inside and outside the discipline is valued through numbers of, and restrictions on, electives. For other external constituents the curriculum signals indirectly the preparation of students and thus relates to factors important to parents and employers.

The first step we took at this point was to identify issues and concerns that arose during the discussions described previously and grouped the desired curricular changes into broad categories, which are shown in Table 1. The curriculum discussions also took into account best practices from [16]. The inclination of those faculty members that were more content-focused was to make changes at the course level in pursuing these objectives, but taking this direct route led to circular discussions and gridlock. The department thus chose to abstract the discussion to talk more broadly about curriculum structural changes that could address multiple desires. A key point is that abstracting the discussion away from individual courses and topics led to more progress on curricular change than past discussions which were more course- and contentfocused. It seems that content will always fill the space that it is given so focusing on structure over content was more productive.

Table 1: High-level interests of students and faculty within the department with regard to what a new curriculum and curricular structure should provide.

\begin{tabular}{|c|c|c|}
\hline Curricular Desires & Student Desires & Faculty Desires \\
\hline $\begin{array}{l}\text { - Support systems engineering } \\
\text { - Introduce teamwork earlier } \\
\text { - Improve communication } \\
\text { skills } \\
\text { - Expand electives }\end{array}$ & $\begin{array}{l}\text { - Desire for more electives } \\
\text { - More flexible curriculum for } \\
\text { studying abroad }\end{array}$ & $\begin{array}{l}\text { Teaching flexibility, e.g. the } \\
\text { ability to teach courses } \\
\text { outside the program. } \\
\text { - No gap semesters for } \\
\text { prerequisite courses. } \\
\text { - More alignment between } \\
\text { electrical and computer } \\
\text { engineering. } \\
\text { - Support liberal arts mission. }\end{array}$ \\
\hline
\end{tabular}

3) Changes to the Curriculum: After initial (failed) attempts to conceptualize change at the individual course level the $40 \mathrm{~K}$ working group started to consider more systemic and structural changes that could address multiple concerns. Through several meetings focused on conceptualizing the curriculum the group identified the following ways to represent more structural curricular changes that could meet the goals identified in Table 1.

- Curricular Threads: View the curriculum as a tapestry that is supported by a small number of major threads (the weft) in which individual courses would be interleaved to meet program goals (the warp). This visual analogy let participants visualize the curriculum as a set of "threads" that supported the major foci of the program. Within a thread there are minimal time gaps between a course and its prerequisite courses. 
- Design: The department used the flexibility inherent to design courses to address topics that were difficult to systematically integrate into content-focused courses. ${ }^{1}$ This led to development of a "design thread" that would run throughout the curriculum.

- Compact Core: Reduce the required set of courses to a small, essential core that would be offered earlier in the curriculum, mostly in the second year.

- Expand Electives: Build from the tighter core to offer more electives in the last two years of the program, and organize elective offerings by defining sets of elective courses as concentrations. Build better alignment with the liberal arts mission of the institution by ensuring each program has at least one free elective slot in every semester.

Throughout the process of re-envisioning the curriculum the group developed an internal language - threads, core vs. concentration electives - to conceptually discuss aspects of the change process that was then used department-wide. Each of these changes is discussed in further detail below

3a) Curriculum Threads: Curriculum threads entered the language of the working group as a visual aid or heuristic that helped the involved faculty discuss the rather abstract design of the curriculum. The term "thread" came to mean a set of courses that have an identifiable theme and was unbroken, i.e. in back-to-back semesters, to allow for maximum transfer of knowledge and skills. The idea originally stemmed from discussions of how the curriculum needed to serve as a representation of the discipline, with the term drawn from tapestry weaving where orthogonal sets of thread, the warp and the weft, create the desired design. Over time the involved faculty identified six threads: math, science, electrical systems, information systems, engineering systems design, and professional skills. The same threads were included in both curricula but the length and composition varied. Given the pragmatic nature of engineers, one theme early in the discussions was how to implement threads. We discussed threading topics and experiences through existing courses, but moved away from this idea given how difficult it was to mandate course content or topics. One aspect of the difficulty of such change was that content-focused courses were seen as "gate-keepers" by some faculty. Thus, courses were assigned to threads with the exception of the introductory course which served as the stepping off point for all of the ECE-related threads.

The math, science, electrical systems, and information systems threads form the core of most ECE programs. No changes were made to the math and science threads beyond expanding the number of electives since the program was already at the lower limit of ABET requirements. The electrical systems thread focuses on electrical engineering topics and the information systems thread focuses on computer engineering topics. These two threads encompass most department courses. In these threads, the major changes were to eliminate some required courses by shifting them to electives; this opened up space in the curriculum and allowed "core" disciplinary content to move from the third to the second year. The goal of shifting material earlier was both to remove pressure from students since the junior year overloaded many individuals as well as introduce disciplinary content earlier. In brief, by moving and reclassifying courses space was opened in the curriculum with only minor changes needed in the content or focus of the courses themselves.

\footnotetext{
${ }^{1}$ This has risen to the level of a key point as well. Courses with traditional, typically content-related names, tend to be completely populated with content only related to that title. It seems difficult for departmental faculty to make space in traditionally named or content named courses.
} 
The most significant changes to courses arose in the design and professional skills threads. The professional skills thread focuses on professional development topics like resume writing and interview skills, talks by alumni and engineers in industry, ethics, entrepreneurship, supply chains, standards and other topics that are difficult to include in content-focused courses. This thread is short and consists of a course in the junior and senior year - but by designating it as a thread it identifies professional development as a key curricular outcome. The course implementing this thread is offered twice per year to enable students more flexibility to pursue study abroad opportunities.

The design thread provides a structure for integrating ECE design into the curriculum by introducing students to various elements of the design model used in our program as shown in Figure 3. In this conception design is considered through lenses of context, function, design process, performance, creation, value creation, and people. Emphasis is placed on how representations capture these elements and how negotiation between these perspectives frames design processes. The design thread introduces students to these seven aspects of design culminating in a full-year capstone design experience where they work with an external client. The creation of the design thread provides the curricular space to address issues raised by our ABET process - systems thinking, communication, and teamwork - that did not fit cleanly into other, content-focused courses. The design thread also focuses on testing, measurement, and engineering judgment which were not explicitly identified during the ABET process, but have consistently come up in discussions within the department. Given the contingent nature of engineering knowledge [17], such skills likely need to be learned and practiced in context.

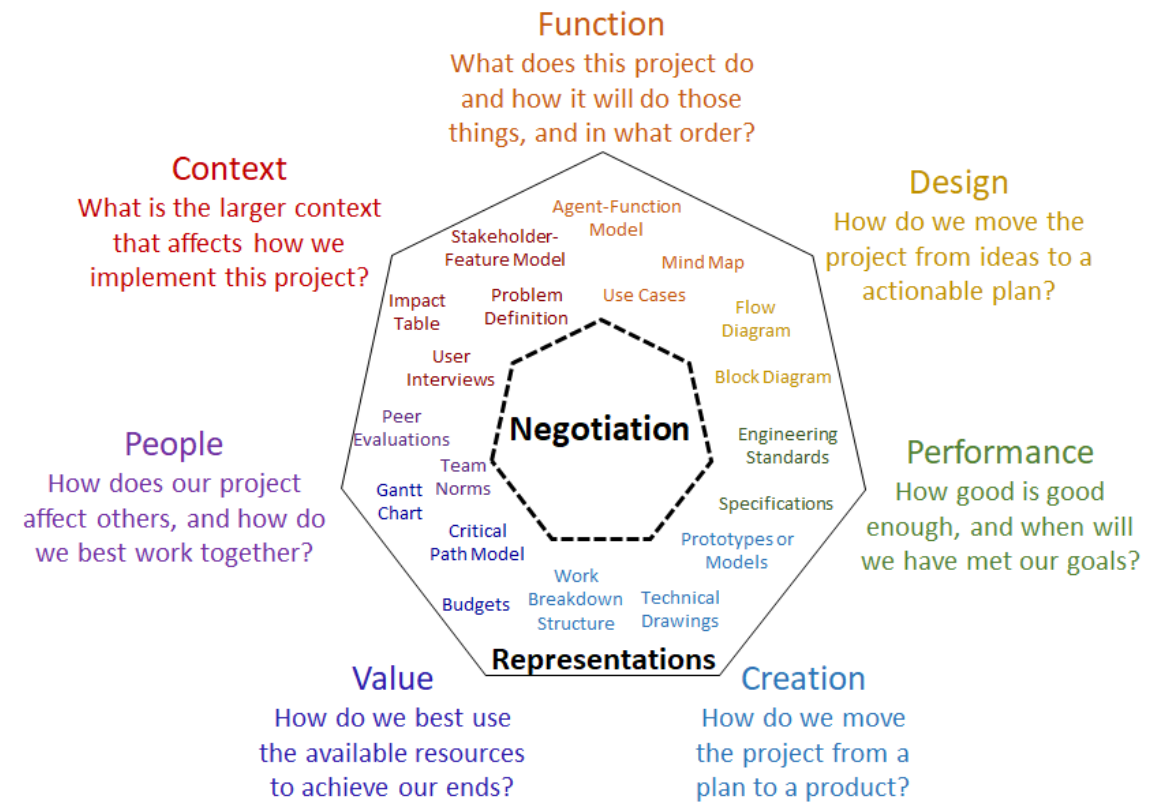

Figure 3: Seven element representation of design focusing on representations and negotiation.

3b) Design as a Solution: For several years before the start of the curricular change process faculty in the department universally recognized more "design" was needed in the curriculum. The faculty did not, however, have a shared conception of design or how much was needed. 
Rather, design was seen both as a place to acquire skills and an area which could be used to address almost all of the ABET outcomes. Thus teaching design was seen as a means to an end, but faculty did not initially share deeply-held implicit assumptions of what design entailed or what learning goals would be accomplished. This led to significant miscommunications on how design courses should be set up and taught. Despite various conceptions of design there was general agreement that it entailed prototyping, fabrication, and testing; that reports and presentations offered opportunities to practice communication; and that systems engineering was a part of design.

These various conceptions of the ends of education were measured by a survey of the faculty members of the working group using Shiro's survey on faculty beliefs derived curriculum theory [9]. As can be seen in Figure 4 below, there was more agreement on curricular ends supporting career preparation (social efficiency) and individual student development (learner centered), but some faculty viewed courses contributing more to preservation of disciplinary knowledge (scholar academic) or larger societal goals (social reconstruction). While ideally the underlying belief systems would be negotiated in a curricular design exercise, there was relatively little patience among engineering faculty who wanted to quickly converge on measurable outcomes.

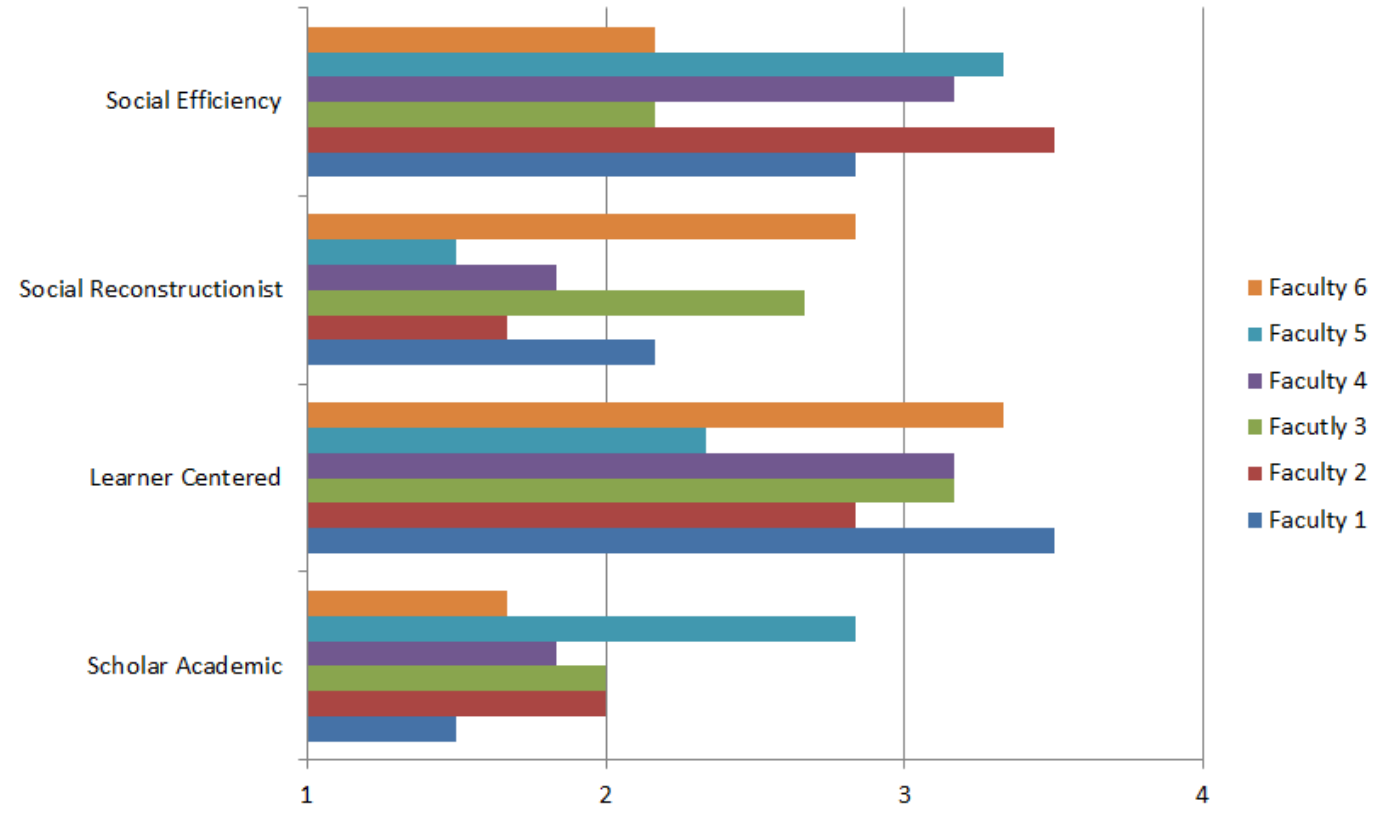

Figure 4: Results from faculty on the 40K Working Group's responses to Shiro's survey [9] on curricular theory.

Although these differences were not resolved, they became visible and the working group of faculty approached the course design exercise with an understanding that others had different perspectives on what design courses should accomplish. For this reason the group decided to adopt an action research [18] approach with the starting point that students should have design in every year of the curriculum. In terms of implementation, all engineering students take a college-wide introductory course in their first semester which offers some elements of design, but this was not changeable at the department level. Thus our conception of design is initially introduced in the first ECE course and is taken in the second semester. This course was revised from an introduction to circuits and digital logic into having students design and build an Internet 
of Things (IoT) device. A half-credit design course in the sophomore year focuses on fabrication, test, and measurement. In the third year another half credit course replaced a written communication course that was generally seen by students as ineffective. In the fourth year, the two-course, full-year capstone course sequence, which consisted of a half-credit and full-credit class, was expanded to two full-credit classes. Overall in a 34 credit program this added 2.5 credits or added about $7 \%$ of the curriculum towards design. Design in each of the four years is described below, with an emphasis on how the courses have evolved over time.

The design thread spans all four years of the curriculum and the role of each course in meeting department objectives is shown in Table 2. The first course in the second semester of the first year, ECEG 100, introduces students to the discipline through design. As this course has developed several goals emerged. One is to focus on block diagrams to provide a view of engineered systems and abstraction. An IoT design project has students design modules that are integrated to sense and measure some aspect of the environment and push the data to the cloud. To support skills in teamwork students work in pairs, but individual demonstrations ensure students divide work fairly and build the necessary technical skills. All topics in the course are connected to later courses since a goal of this course is to explain the curricular threads and help students understand both how courses are related in the curriculum and when topics introduced in the first year are covered in more depth in subsequent courses. Students submit formal design reports with scoring focusing on appropriate communication of process, implementation, and results.

The second course, ECEG 201, focuses on the design, performance, and creation aspects of design shown in Figure 3. The goal is to give students skills and confidence in building and testing electronic devices so that rapid prototyping is not seen as a barrier in later courses. This course has students work individually but collaboratively to create a digital display device that measures local sensors or can pull data from the cloud. The project is heavily scaffolded, walking students through modeling circuits; designing, fabricating, and testing printed circuit boards; collecting, analyzing, and displaying performance data; how to design and fabricate enclosures; and coding embedded controllers. This course relies heavily on an electronicsfocused makerspace that houses PCB fabrication and assembly equipment, basic and advanced soldering and desoldering equipment, basic and advanced electrical test and measurement equipment, basic mechanical fabrication equipment (3D printing and laser cutting), and computer design tools. One goal of the design thread was to get students working with the equipment in the makerspace as early as possible. We see the abilities to fabricate and test as major prerequisites to understanding and being able to carry out creation.

In the third course, ECEG 301, students are led through a structured and scaled down version of the capstone course with students going from problem identification to building a second integrated version of their system. The only aspect within the course completely new to students is problem identification-they have been exposed to the other elements of our design in prior courses. In bringing together the entire design process, the steps students move through roughly includes: problem exploration and identification, planning, subsystem development, and system development. As with the capstone course, there is a second iteration of the system at the end allowing students to learn from their first system integration and improve. The course is structured around students working in small teams of three or four within a context of the NAE 
Grand Challenges for the course and projects. Students, with some oversight, are allowed to explore and select a problem within a Grand Challenge. Overall teams are given an incredible amount of agency with regard to the problem and project as long as they support their decisionmaking through research. Teams represent their project using a minimal set of representations: architecture, mechanical, and behavioral. The entire process and approach mimic what students later see in the capstone course sequence, but at a smaller scale in all respects.

Table 2 - Specific ways each design thread course addresses ABET issues.

\begin{tabular}{|c|c|c|c|c|}
\hline Course & Communication & Systems Thinking & Teamwork & $\begin{array}{c}\text { Problem } \\
\text { Identification }\end{array}$ \\
\hline ECEG 100 & $\begin{array}{l}\text { Use of block diagrams } \\
\text { throughout the course. } \\
\text { Focus on appropriate } \\
\text { language in reports. }\end{array}$ & $\begin{array}{l}\text { Project with modules. } \\
\text { Introduction of basic } \\
\text { ECE systems model. }\end{array}$ & $\begin{array}{l}\text { Work in pairs on a } \\
\text { project. } \\
\text { Explicit division of } \\
\text { tasks with individual } \\
\text { demos. }\end{array}$ & Not included. \\
\hline ECEG 201 & $\begin{array}{l}\text { Individual structured } \\
\text { reports that mimic } \\
\text { datasheets. }\end{array}$ & $\begin{array}{l}\text { Framing design in } \\
\text { abstraction through } \\
\text { the use of block } \\
\text { diagrams. }\end{array}$ & $\begin{array}{l}\text { Individual work with } \\
\text { collaboration } \\
\text { encouraged. }\end{array}$ & $\begin{array}{l}\text { Introduced after } \\
\text { successful completion } \\
\text { of device to frame use. }\end{array}$ \\
\hline ECEG 301 & $\begin{array}{l}\text { Appropriate technical } \\
\text { language. } \\
\text { Use of a small set of } \\
\text { representations. }\end{array}$ & $\begin{array}{l}\text { Projects are complex } \\
\text { enough to be broken } \\
\text { down across a team. } \\
\text { Focus on multiple } \\
\text { levels of } \\
\text { representations. }\end{array}$ & $\begin{array}{l}\text { Work in teams of } 3 \text { or } \\
4 . \\
\text { Collaborative work } \\
\text { model - divide and } \\
\text { conquer. } \\
\text { Mix of team and } \\
\text { individual demos. }\end{array}$ & $\begin{array}{l}\text { Teams identify an } \\
\text { NAE GC of interest } \\
\text { and a problem to solve } \\
\text { on their own. }\end{array}$ \\
\hline $\begin{array}{l}\text { ECEG } 400 \\
\text { and } 401\end{array}$ & $\begin{array}{l}\text { Appropriate technical } \\
\text { language. } \\
\text { Use of a large set of } \\
\text { possible } \\
\text { representations. }\end{array}$ & $\begin{array}{l}\text { Large projects with } \\
\text { multiple possible } \\
\text { approaches. } \\
\text { Focus on multiple } \\
\text { levels of } \\
\text { representations. } \\
\text { Explicit system } \\
\text { engineer position on } \\
\text { the team. }\end{array}$ & $\begin{array}{l}\text { Teams of } 6 \text { or } 7 \\
\text { students. } \\
\text { Collaborative work } \\
\text { model with } 3 \text { different } \\
\text { roles on the team. } \\
\text { Mix of team and } \\
\text { individual demos. }\end{array}$ & $\begin{array}{l}\text { Teams work with an } \\
\text { external client with a } \\
\text { submitted idea. } \\
\text { Teams follow lean } \\
\text { startup approach. }\end{array}$ \\
\hline
\end{tabular}

The final capstone sequence, ECEG 400 and ECEG 401, spans the entire senior year. It has been co-managed by a faculty member in EE and one in CPE to ensure both disciplinary perspectives are represented. The capstone course has been described elsewhere [19], but in short faculty provide significant autonomy to large student teams of six or seven with a dedicated project manager and system engineer. The course focuses on formal representations of the seven aspects of design shown in Figure 3 as student teams develop projects for external clients. Due to the relatively hands-off approach supported by feedback on design representations there is significant student ownership of the projects and communication with the project clients. Feedback from students following graduation shows that the focus on autonomy and emphasis on a holistic $360^{\circ}$ view of project needs through representations serves to help students transition from an academic setting to the workforce. 
While these courses continue to develop and adapt through action-based research, there are several broad conclusions that can be drawn. First, communication, representations, and systems thinking are tightly coupled. Without the ability to communicate ideas through widelyunderstood abstract representations appropriate to a discipline, it is nearly impossible to do any type of system decomposition and design. As we changed our capstone courses to include more complicated projects that required students to think at multiple levels of abstraction, we found students had difficulty architecting systems since courses earlier in the curriculum did not explicitly focus on systems or abstraction. Since the program identified as a content- and labfocused curriculum with emphasis on fundamentals there was little emphasis on developing broader, systemic understanding. As a result of the change efforts the department has started to talk about the differences between design-focused and lab-focused curricula. The development of design courses also highlighted that discrete lab experiences do not necessarily transfer when working on projects. While far transfer is difficult or impossible to achieve, we believe that the structured nature of labs leaves students little space to develop their own metrics, tests, or judgement. There seems to be a balance between consistency and conformity of learning experiences and the level at which students engage.

As the change effort has developed over time, one concern about the design thread is the ability to sustain it over time. The original intention was to cycle faculty through design courses so they could better understand student abilities to apply knowledge from more theory-based courses and have electrical and computer engineering faculty co-teach the design courses to balance disciplinary perspectives. However as we converged on a shared notion of design, only a subset of the faculty have expressed an interest in teaching in this space. As hiring and fiscal pressures lay waste to our dreams, we have adapted by having the faculty who are not interested in teaching in the design space serve on an evaluation panel in the capstone course. Faculty evaluators gain insight into what the students transfer from past classes, which in turn stimulated further discussions on teaching and curriculum.

3c) Compact Core: Adding the design and professional skills thread and additional electives to the curriculum required creating curricular space. One of the mantras of the $40 \mathrm{~K}$ Working Group was that the real challenge in curricular change was not what to add, but what to eliminate. The approach we took, which was necessary but politically challenging, was to reduce the number of required, core courses. This was difficult since for many faculty the default definition of necessary core courses is "what I teach". An analysis of the curriculum showed that before the curricular change the curriculum had a hierarchical structure with science and math courses predominating in the first year, additional science and math and foundational ECE courses (e.g. circuits and digital logic) in the second year, courses on core topics in the third year, and specialty and elective courses in the fourth year. It was generally agreed within the working group that moving some of the core disciplinary courses to the second year would be beneficial by engaging students in the discipline earlier and would also allow for more electives. Additionally, due to the prevalence of transfers between the two degree programs, a goal was to make the first two years as identical as possible to limit the impact on students who shifted programs. In the final design, the curriculum addresses most core topics by the end of the second year.

Changing required courses was one of the most time consuming aspects of the change process since it was difficult to achieve consensus. We found, however, that one of the reasons required 
courses were staunchly defended was that faculty sought to attract students to, and teach more courses in, their own sub-field. Thus a selling point of the curricular change was that it would be possible to implement topical concentrations (described in the next section) if the number of courses in the "core" were reduced. The final compromise was realized by reducing the amount of time spent on circuits from 3 credits to 2 credits, removing a half-credit technical writing course, moving required courses to selected electives (i.e. take X of Y), shifting engineering science courses such as mechanics and materials to electives within a concentration, and giving faculty autonomy over the design of areas of concentration. One additional effect of these changes is that by reducing the size of the "core" we managed to increase student agency which aligned with the liberal-arts mission of the institution.

3d) Concentrations and Electives: As discussed above, the idea of a lean core alone was not initially palatable to everyone in the department without having a way for students to specialize in topical areas. As a result we adopted the idea of area concentrations from another program on campus. A concentration is a credential that appears on a student's transcript and is composed of three to five elective courses that relate to a particular topical area within the discipline where there are a sufficient number of faculty to offer elective courses. Faculty within a concentration area have significant autonomy to configure the concentration requirements. Some concentrations have minimalist requirements and accept a broad range of courses. Others have chosen to require students to devote a larger number of elective courses from a more limited list of options to gain the concentration. Many concentrations include courses outside the department, including required engineering science courses in the previous curriculum as well as other STEM courses.

The intent of allowing a variety of concentrations was both to achieve faculty buy-in and to encourage a flexible structure that would make it easier for offerings to evolve over time. In essence the change to curricular structure gives faculty more autonomy in topical areas to update courses and create new courses as knowledge in the discipline changes and to attract students to elective courses. At PALACE courses without a minimum enrollment won't be offered. While concentrations effectively have expanded the number of electives offered as the program's ABET review suggested, there are several disadvantages to this approach. One is that concentrations make course scheduling difficult since sufficient courses have to be offered to allow students to take any concentration. To address this issue we have had to move to a two year course rotation schedule, which can create difficulties in adjusting the schedule to leaves and sabbaticals. In summary, while setting up area concentrations allowed the curriculum change to be implemented, it turned out to be important to structure the change in a way that allows flexibility both in requirements and scheduling. At this juncture it is difficult to tell if the additional workload involved is worth it.

Another topic related to student choice and agency that at times was contentious was the number of electives in the curriculum. In the conversation on electives the $40 \mathrm{~K}$ Working Group identified free electives for which a student could take any course, general education electives which had to be in a particular area such as humanities or social sciences, math or science electives, restricted technical electives where students took two of five possibilities, and technical concentration electives that were needed for a concentration. Since PALACE is a liberal arts institution one of the design goals of the planning group was to allow students the 
maximum possible flexibility in choosing courses. Historical data on student course selections indicated that about $25 \%$ of students who come to PALACE could be classified as "dualists" who pursue a minor or even a second major in non-engineering discipline, another $25 \%$ are "explorers" who take a seemingly random selection of elective courses, and 50\% are "purposedriven" who use open electives to take more engineering-related courses, particularly in computer science. Although the planning group operated under the assumption that maximizing open electives would best serve all three groups of students, there was push-back from some faculty who thought that offering too many free electives would not encourage students to take "the line of greatest advantage over the path of least resistance". After significant deliberation the revised curriculum added one free elective going from four to five, added no general education electives (kept at five), went from one to two math or science electives, and from one to four technical electives. This was an increase of six courses or about $18 \%$ of the overall curriculum. Students can take at least one course of their choosing each semester - we believe that this is a major accomplishment.

\section{The View from the Start of Other Side}

At the time this case study was written the class that entered under the new, design-focused curriculum is in their final, fourth year. Over $80 \%$ of students at PALACE who matriculate graduate in four years. At this point in time faculty memories of implementation are relatively fresh and the department is actively addressing various unanticipated issues that have arisen with a curricular change of this magnitude. This section reflects [20] on the change process at one point in a longer journey. Where available, reflections are supported by data, but primarily this reflection relies more upon a bricolage approach [21] rather than the CQI ABET process in seeking to ask whether the significant effort involved has been worthwhile. In other words, the reality of change is that it is rarely done with high fidelity and often uses the tools available at hand in achieving desired goals. Thus the results are different than the ideals or participants' conceptions of what the results of change should be. Here we reflect on the results of the process described previously and to what extent has the program met the goals envisioned and to what extent have the original goals changed by utilizing the tools at hand.

One of the initial goals was to address common curricular concerns raised by students over multiple years of the program: having access to a small number of electives and lack of access to opportunities such as study-abroad programs. As described above the number of elective courses increased by six out of 34 credits, or an $18 \%$ increase. This increase is primarily driven by the addition of area concentrations which enable faculty to teach more courses in areas they are personally passionate about. While more elective courses are being taught, with a small faculty questions of sustainability are beginning to arise, particularly as faculty who designed narrow concentrations with more rigid requirements go on leaves or sabbaticals, potentially leaving students fewer options. Going forward it is anticipated that there will be a period in which concentration requirements are adjusted to balance specificity with sustainability. An unanticipated effect is that by having a smaller set of core courses with the ability to apply a wide range of electives to a concentration it is easier for students to transfer into the degree program. While low retention is often considered an issue in engineering education, data shows [22] that what appears to be low retention is actually high barriers to transfer due to rigid curricular structures. 
In terms of providing curricular flexibility for study abroad, scholarship athletes, and other cocurricular activities the changes seem to have been successful. By moving required disciplinary courses to the first two years it becomes easier for students to find courses that can be accepted for transfer credit if they wish to study abroad in their third year. Allowing more electives also supports acceptance of transfer credit as does offering design and professional skills courses in both semesters since these are more difficult to find equivalent courses for. Notwithstanding COVID-19, we have seen an uptick in the number of students who are studying abroad and will continue to track the impact of this change based on student feedback through an annual survey by our IEEE student group.

Faculty also had curricular concerns, however these concerns varied by each individuals' beliefs about curriculum. One concern held by many faculty that the change tried to address was a lack of flexibility in teaching assignments. Prior to the change the curriculum focused on covering a wide range of topics through a large number of required courses, but the topics did not always align with faculty expertise or preparation as turnover occurred or individuals went on leave. The result was that personnel changes could make offering required courses problematic. While having a more concentrated core addressed this concern, faculty transferred the topically-focused view to concentrations, creating similar issues. In devising concentrations as a way to bargain for change the planning team failed to recognize that this approach may have reinforced a topical focus. The shift to offering more electives did, however, address another faculty concern of better aligning to the liberal arts mission of the university. The degree to which engineering students are given curricular agency is ultimately a question of program identity and matters in student recruitment and how the department is perceived by colleagues across the institution. While there were disagreements in how, there was consensus among the faculty that we should seek to align with the institutional mission; again the devil is in the details as faculty espouse the liberal arts mission but are not always willing to enact changes that support it in practice.

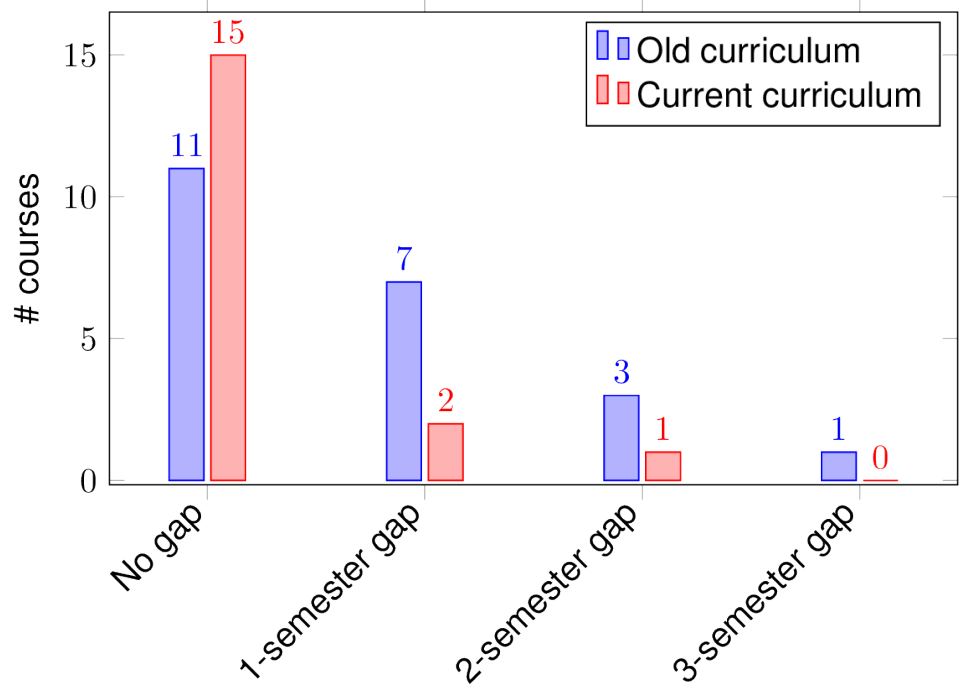

Figure 5 - Change in number and temporal gaps of prerequisite between old and current curriculum.

Another area of faculty curricular concern was that courses and their prerequisites often had gaps of one or more semesters. Given the high four year graduation rate at PALACE temporal gaps 
came about from curricular complexity more than students getting off-track. Visualizing the new curriculum as threads significantly improved this situation. Not counting elective courses where prerequisites become complicated, in the curriculum prior to embarking on this change process, there were 22 listed pre-requisites of 36 courses. Of these, eleven courses were sequential with no gap between them. Seven courses had a prerequisite that were taken with a one semester gap, three courses had two semester gaps, and one course had a three semester gap. In the new curriculum there are 18 prerequisites for the 36 courses, fifteen have no gap, two have a one semester gap, and one has a two semester gap; each gap occurs between courses in different threads. Thus the visualization of a curricular tapestry with threads was successful in reducing curricular hierarchy and ensuring a more continual flow of course topics. These changes are summarized in Figure 5. We are currently evaluating how these changes affect transfer.

A shared goal of undertaking curricular change was to increase the amount of design in the curriculum. As discussed previously, 2.5 credits, or $7 \%$ of the curriculum, of design were added in the design thread which stretches across all four years of the curriculum. It turned out that while faculty agreed there should be more design in the curriculum, this did not mean everyone was equally willing to teach design. The reason for this shift was likely because the change process helped define design in a way that was more consistent (allowing less personal interpretation) than the conceptions individuals previously held. While having common definitions were felt to be necessary for creating a coherent thread in the curriculum, it may have alienated individuals who viewed design as application of engineering science principles rather than with a focus on user-centered approaches with a strong focus on problem definition. If the planning group were able to redo the discussions it would have been helpful to elicit perspectives on individuals' definition of design throughout the process - in this design effort we failed to follow good principles of user-centered design by defining design as user-centered.

Creating more alignment between the electrical and computer engineering degree programs was another goal that was driven by feedback from industry representatives on their expectations for graduates, feedback from electrical engineering students who felt under-prepared in coding, as well as the more logistical requirements of offering two degree programs in a small department. The curricular changes, particularly moving core courses into the second year accomplished this goal. The difference between the programs dropped from three courses to one course, an ABETmandated math course for computer engineers. Students also appear to see themselves as part of a single cohort to a larger extent and the number of transfers between programs has increased, although numbers are still small.

One of the desired changes, at least for the department chair, was to develop a more systemic and less provincial view of the degree programs. One of the sayings of the $40 \mathrm{~K}$ working group was "to a hammer every problem looks like a nail, but to a faculty member every problem looks like a new course." One of the most profound changes, and one where attitudes are still evolving, is that department faculty have become better at considering the curriculum as a whole, rather than individual courses in understanding educational outcomes. This shift in attitudes is by no means achievement of nirvana, faculty still bicker and individuals still seek to protect their interests. Rather, faculty have gained what might be termed a wide angle lens that supports language for broader and more forward-looking discussions. While such dialog in some ways is a desired outcome of ABET accreditation, this shift in attitudes was not a direct result of the ABET 
process, but is better attributed to seeking change desired by faculty rather than driven by an externally mandated CQI process. The shift in attitudes comes more from seeing the curriculum as a set of opportunities and affordances for students to learn rather than as a means to achieve specified learning outcomes. In other words while still fragile, the change process enabled faculty to take pride in, and ownership of, the curriculum, seeing it as an end in itself rather than as a means to ABET-mandated ends. It seems as if providing increased agency is as important for faculty as it is for students.

In summary, the change process mostly succeeded in addressing explicit goals, although from the far side the changes are more nuanced and complex than they first appeared. Beyond making programmatic changes the involved faculty have also gained some insights on our change process that were not clear at the beginning. First, words and language are important. Time and time again during this process faculty arguments occurred because we were using the same word without having a shared definition. Spending the time to talk and then document the language used plays an important role in change. Second, it is important to make time and space for the hard conversations. Rather than adopt a timeline-driven engineering process, in the early stages faculty spent a lot of time doing scaffolded reflections on their own beliefs about engineering and education. Common ground needs to be built upon and differences need to be acknowledged and discussed in order to understand others. While this did not always occur in our process, better progress was made when faculty focused on the constructive differences between different perspectives. These conversations were often heated and exposed deep epistemological and pedagogical differences between faculty, some of which were not resolvable. It is important to acknowledge tensions without having to resolve them. However it is also important to recognize the difference between sincere disagreement and simply being contrarian.

A third insight is that change at the curricular level does not necessarily align with the more course-level focus of many ABET evaluators. As mentioned previously the goal of our change process was not to improve what we were doing, but rather change what we were doing. During the program's most recent ABET evaluation we found program evaluators often focused on incremental, individual course changes more than - or rather, instead of - the systemic curricular restructuring that took place. ABET's implicit emphasis on continuous, incremental change in courses as codified in CQI processes does not sufficiently recognize discrete and systemic change at the curricular level. It is thus an open question of whether continuous improvement processes as implemented by ABET fosters or deters innovation. A fourth, related insight is that change at the course level does not necessarily lead to lasting change. Our change processes were more effective the more abstracted they were. Such abstraction needs to feed back to actions, but the bi-directional "vector of abstraction" is important in curricular change [23].

In terms of design specifically, it has been extremely difficult to build shared conceptions of design, and the attempt to do so has unnecessarily polarized faculty. While our program initially sought to have design courses be "where the rubber meets the road" in terms of faculty seeing students' ability to apply concepts and practically integrate electrical and computer engineering, this was difficult to achieve due to resource constraints. At the present time we have restarted regular discussions of interested faculty with the goal of making the design thread more sequenced and coherent. Having a common conception of design, the seven-element model of Figure 3, provides an artifact to center these discussions. The program faculty have, however, 
come to increasingly acknowledge the human elements of design rather than focusing purely on technical elements. Human problems and creating shared meaning are at the core of a design process. Without shared definitions and meaning, unstated assumptions have potential to stop design processes before it can begin.

\section{Conclusion}

This exercise has exposed that the goals of a department and its faculty, staff, and students go far beyond curriculum. This change process, spanning slightly less than a decade, exposed the limitations of courses as a sole means of stimulating student development. All change processes are embedded in local needs. For the electrical and computer engineering department at PALACE these are enrollment pressures, a lack of identity due to the breadth of the discipline, and many pathways our students pursue after graduation.

This snapshot has looked backwards at over five years of change processes. The experience with change - both productive and not - led the program to submit an NSF RED proposal to support further change efforts. The proposal was subsequently funded [EEC 2022271] and built on many of the experiences outlined in this publication. While success in grant-writing depends on many factors, the experience with change helped the PIs articulate a central vision and specific actions for the program that was compelling. Future case studies will explore the transition from local efforts to using external resources to achieve more systemic impact.

This material is based upon work supported by the National Science Foundation under Grant No. 2022271. Any opinions, findings, and conclusions or recommendations expressed in this material are those of the author(s) and do not necessarily reflect the views of the National Science Foundation.

\section{Citations}

[1] A. J. Kezar, "Understanding and Facilitating Organizational Change in the 21st Century: Recent Research and Conceptualizations," Los Angeles, 2001.

[2] M. Connolly and E. Seymour, "Why Theories of Change Matter (Examples from EHR Programs)," National Science Foundation, Washington, DC, 2012.

[3] J. Ellis, "Special Session - Does Size Matter? Small Programs Contribute as Many Graduates to the Engineering Workforce as Large Programs Do," Frontiers in Education. Sarasota Springs, NY, 2008.

[4] National Science Board, "Science and Engineering Indicators 2016," Natl. Sci. Board, p. 897, 2016.

[5] D. Kotys-Schwartz, D. Knight, and G. Pawlas, "First-Year and Capstone Design Projects: Is the Bookend Curriculum Approach Effective for Skill Gain," American Society for Engineering Education Annual Conference \& Exposition. Louisville, KY, 2010.

[6] J. S. Fairweather, "Linking Evidence and Promising Practices in Science, Technology, Engineering, and Mathematics (STEM) Undergraduate Education," National Research Council's Workshop Linking Evidence to Promising Practices in STEM Undergraduate Education. National Academy of Engineering, Washington, DC, 2011. 
[7] C. Henderson, A. Beach, and N. Finkelstein, "Facilitating change in undergraduate STEM instructional practices: An analytic review of the literature," J. Res. Sci. Teach., vol. 48, no. 8, pp. 952-984, 2011.

[8] Kern Family Foundation, "KEEN Engineering Unleashed.” 2019.

[9] M. S. Schiro, Curriculum Theory: Conflicting Visions and Enduring Concerns. Thousand Oaks, CA: Sage, 2012.

[10] D. M. Gilbuena, B. U. Sherrett, E. S. Gummer, A. B. Champagne, and M. D. Koretsky, "Feedback on professional skills as enculturation into communities of practice," J. Eng. Educ., 2015.

[11] L. Bucciarelli, Designing Engineers. Cambridge, MA: The MIT Press, 1996.

[12] M. Rokeach, Beliefs, attitudes, and values: a theory of organization and change. San Francisco: Jossey-Bass, 1968.

[13] A. L. Pawley, "Universalized Narratives: Patterns in How Faculty Members Define 'Engineering,", J. Eng. Educ., vol. 98, pp. 309-319, 2009.

[14] L. R. Lattuca, P. T. Terenzini, J. F. Volkwein, and G. D. Peterson, "The Changing Face of Engineering Education," Bridg., vol. 36, no. 2, pp. 3-13, 2006.

[15] R. Barnett and K. Coate, Engaging the Curriculum in Higher Education. London: Open University Press, 2004.

[16] J. Mehta, “An Economics Lesson: Teaching for Disciplinary Understanding," Education Week, 2015. [Online]. Available: https://www.edweek.org/teaching-learning/opinion-aneconomics-lesson-teaching-for-disciplinary-understanding/2015/01.

[17] S. L. Goldman, "Why we need a philosophy of engineering: a work in progress," Interdiscip. Sci. Rev., vol. 29, pp. 163-176, 2004.

[18] G. M. Bodner and M. Orgill, Theoretical Frameworks for Research in Chemistry/Science Education. New York: Prentice-Hall, 2007.

[19] R. A. Cheville and M. S. Thompson, "Navigating Process-Product Tensions using a Design Canvas," in ASEE Annual Conference and Exposition, Conference Proceedings, 2018.

[20] E. Rose, On Reflection. Toroto: Canadian Scholars' Press, 2013.

[21] C. Levi-Strauss, "Chapter One: The Science of the Concrete," in The Savage Mind, 1962.

[22] C. J. Atman et al., "Enabling Engineering Student Success: The Final Report for the Center for the Advancement of Engineering Education," San Rafael, CA, 2010.

[23] J. Krupczak and G. Bassett, "Work in progress: Abstraction as a vector: Distinguishing engineering and science," in Proceedings - Frontiers in Education Conference, FIE, 2012. 